\title{
Areally-averagei overland flow equations at hillslope scale
}

\section{GOKMEN TAYFUR \& M. LEVENT KAVVAS}

To cite this article: GOKMEN TAYFUR \& M. LEVENT KAVVAS (1998) Areally-averagei overland flow equations at hillslope scale, Hydrological Sciences Journal, 43:3, 361-378, DOI:

10.1080/02626669809492132

To link to this article: http://dx.doi.org/10.1080/02626669809492132

曲 Published online: 25 Dec 2009.

Submit your article to this journal $\widetilde{ }$

Џll Article views: 113

Q View related articles $\sqsubset$

Citing articles: 15 View citing articles 


\title{
Areally-averaged overland flow equations at hillslope scale
}

\author{
GOKMEN TAYFUR \\ Department of Civil Engineering, Izmir Institute of Technology, Izmir 35230, Turkey \\ e-mail: tayfur@likya.iyte.edu.tr \\ M. LEVENT KAVVAS \\ Department of Civil and Environmental Engineering, University of California, Davis \\ California 95616, USA \\ e-mail: mkavvas@ucdavis.edu
}

\begin{abstract}
Microscale-averaged inter-rill area sheet flow and rill flow equations (Tayfur \& Kavvas, 1994) are averaged along the inter-rill area length and rill length to obtain local areally-averaged inter-rill area sheet flow and rill flow equations (local-scale areal averaging). In this averaging, the local areally-averaged flow depths are related to the microscale-averaged flow depths at the outlet sections (downstream ends) of a rill and an inter-rill area by the assumption that the flow in these sections has the profile of a sine function. The resulting local areally-averaged flow equations become time dependent only. To minimize computational efforts and economize on the number of model parameters, local areally-averaged flow equations are then averaged over a whole hillslope section (hillslope-scale areal averaging). The expectations of the terms containing more than one variable are obtained by the method of regular perturbation. Comparison of model results with observed data is satisfactory. The comparison of the model results with those of previously developed models which use point-scale and large-scale (transectionally) averaged technology indicates the superiority of this model over them.

\section{Equations d'écoulement de surface en moyen superficiel a l'échelle} du halus

Résumé Les équations d'écoulement des fourches et d'écoulement en couche superficielle moyenne localement entre les deux fourches (Tayfur \& Kavvas, 1994) sont integrés le long des fourches et de la surface entre celles-ci, à fin d'obtenir les équations d'écoulement de surface en moyen superficiel (à l'échelle locale). A cet égard, les hauteurs d'écoulement moyen locales au point de décharge des fourches (bouts avals) et à la surface entre les fourches, en assumant que l'écoulement das ces section a un profil d'une fonction de sinus. Les equations d'écoulement en moyen superficiel qui en resultent dépendent seulement du temps. A fin di minimiser les efforts de calcul et économiser le nombre des paramètres du modèle, le moyen de ces équations son formés sur une section de talus entier (moyen superficiel à l'échelle du talus). Les estimations des termes contenant plus d'un variable sont obtenues par le méthode de perturbation regulière. La comparaison des résultats du modèle avec les valeurs d'observations est satisfaisant. La comparaison des resultats du modèle avec ceux des modèles développés antérieurement avec une technologie de calcul du moyen à échelle ponctuelle ou grande (transectionnelle) montre la supériorité du nouvel modèle.
\end{abstract}

\section{INTRODUCTION}

In nature, land surfaces contain irregular microtopography as opposed to the smooth surfaces which are commonly assumed in the literature. Tayfur et al. (1993) studied 
the flows over such irregular microtopographic surfaces and pointed out the importance of microtopograhy on flow variables such as flow depths and flow velocities which are, in turn, the controlling factors of erosion and sediment transport from such surfaces. Tayfur et al. (1993), at the same time, pointed out the need for smoothing the irregular microtopography in order to conform to the gradually-varied flow assumption embedded in the depth-averaged flow equations.

Irregular microtopographic surfaces also contain rills. The importance of rills on flow dynamics and sediment transport has been well observed experimentally in field and laboratory studies (Emmett, 1978; Meyer et al., 1975; Moss \& Walker, 1978; Abrahams et al., 1989; Abrahams \& Parsons, 1990; Govindaraju \& Kavvas, 1992). In terms of modelling overland flows with combined inter-rill area sheet flow and rill flow, Kavvas \& Govindaraju (1992) simplified the problem by assuming that the flow at inter-rill areas is in one dimension, there is no interaction between rill and adjacent inter-rill areas, and the hillslope surface is smooth. Tayfur \& Kavvas (1994) developed a more comprehensive model for simulating the overland flows composed of interacting rill flow and inter-rill area sheet flows. Unlike Kavvas \& Govindaraju (1992), Tayfur \& Kavvas (1994) considered the actual microtopographic surface. They first averaged the depthaveraged inter-rill area sheet flow equations over an individual inter-rill area width in order to obtain microscale-averaged inter-rill area sheet flow equations (microscale averaging) (Fig. 1). By performing local averaging, they avoided solving the flow at inter-rill areas in two dimensions and obtained the mathematical term representing the interaction occurring between rill and adjacent inter-rill areas. Then, in order to minimize the computational efforts and to economize on the number of model parameters, Tayfur \& Kavvas (1994) averaged the microscale-averaged inter-rill area sheet flow and cross-sectionally averaged rill flow equations over a transect of a hillslope (large-scale averaging)

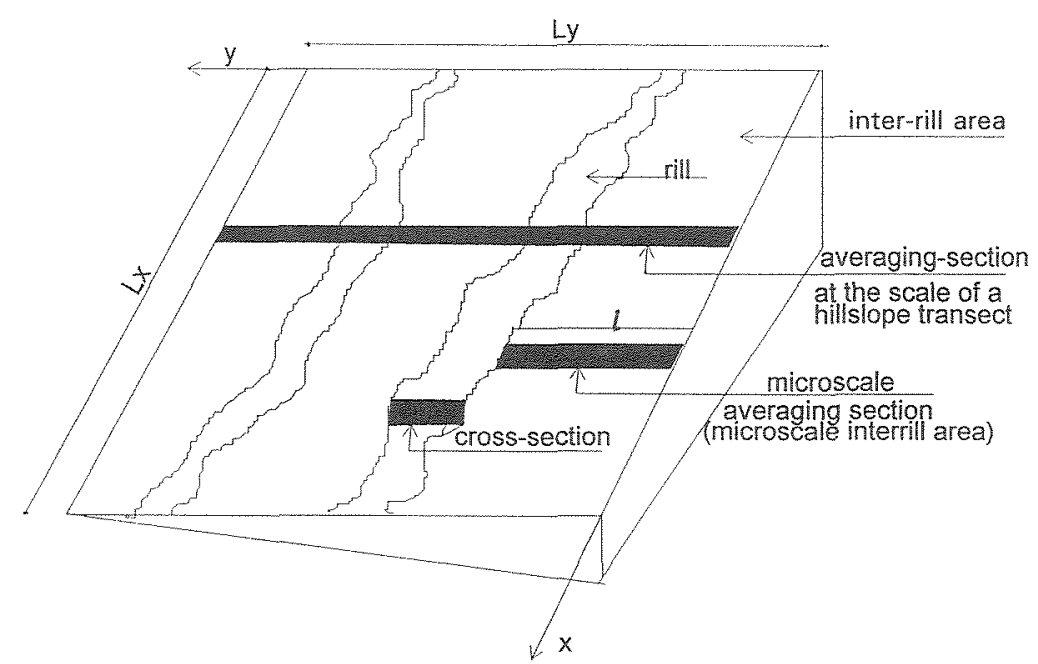

Fig. 1 Microscale and transectional averaging sections for inter-rill area and rill flows. 
(Fig. 1). In order to obtain the closed form of the large-scale averaged equations, they had to develop equations for the mean flow depth for each flow dynamic. This resulted in a system of four nonlinear equations with four unknowns which were solved by Newton-Raphson iterative procedure. They then routed the flow downstream from hillslope transect to transect toward the stream channel.

In real-world problems, one never has the detailed microtopograhic information at a very fine scale to employ the point-scale depth-averaged flow equations. Though the Tayfur \& Kavvas (1994) model does not require information at a point scale, it requires the average values of model parameters (i.e. local slopes, surface roughness) at a transect of a hillslope. In their modelling efforts, Tayfur \& Kavvas (1994) were able to consider a transect thickness of $60 \mathrm{~cm}$ since they had such detailed information. In reality, one may have difficulty in obtaining such detailed information as well. At best, one can expect to estimate average values of model parameters for the scale of a whole hillslope by means of digital elevation information (digital elevation map) with a standard resolution of about $30 \mathrm{~m}$. Therefore, there is a need to develop equations for overland flows composed of interacting rill flow and inter-rill area sheet flow which conserve the mass and momentum at a hillslope scale.

The aim of this study is to develop these areally-averaged interacting rill and inter-rill area overland flow equations which conserve the mass and momentum at the scale of a hillslope.

\section{MATHEMATICAL DEVELOPMENT}

The model to be developed in this study is based on kinematic wave approximation (KWA) of both rill and sheet flows. The flow at inter-rill areas is conceptualized as two-dimensional and having the dynamics of sheet flows. On the other hand, the flow in rills is conceptualized as one-dimensional and having the dynamics of channel flows.

\section{Local-scale areal averaging of two-dimensional sheet flows}

A KWA equation for two-dimensional sheet flows can be expressed as (Govindaraju et al., 1992):

$$
\frac{\partial h_{o}}{\partial t}+\frac{\partial}{\partial x}\left(K_{x} h_{o}^{1.5}\right)+\frac{\partial}{\partial y}\left(K_{y} h_{o}^{1.5}\right)=q_{l}
$$

where

$$
K_{x}=\frac{C_{z} S_{o x}^{0.5}}{\left[1+\left(\frac{S_{o y}}{S_{o x}}\right)^{2}\right]^{0.25}}
$$




$$
K_{y}=\frac{C_{z} S_{o y}^{0.5}}{\left[1+\left(\frac{S_{o x}}{S_{o y}}\right)^{2}\right]^{0.25}}
$$

and $h_{o}=$ sheet flow depth; $q_{l}=$ net lateral flow (rainfall minus infiltration); $S_{o x}$ and $S_{o y}=$ bed slopes in $x$ - and $y$-directions, respectively; and $C_{z}=$ Chezy's roughness coefficient for inter-rill area sections.

Equation (1) is a nonlinear two-dimensional depth-averaged equation which conserves the mass and momentum at a point scale. Consequently, it requires a point information of physical model parameters. Tayfur \& Kavvas (1994) averaged equation (1) over an individual inter-rill area width $(l)$ in order to obtain a microscale-averaged sheet flow equation (Fig. 1). In this microscale averaging, they assumed that the flow at the inter-rill area section has the profile of a sine function based upon the earlier results of Govindaraju et al. (1988). They treated the inter-rill area width $(l)$ as being a random variable and stochastically independent of $x$ direction. The details of this averaging can be obtained from Tayfur \& Kavvas (1994). The resulting microscale-averaged sheet flow equation is (Tayfur \& Kavvas, 1994):

$$
\frac{\partial \bar{h}_{o}}{\partial t}+\frac{\partial}{\partial x}\left(K_{x}^{\prime} \bar{h}_{o}^{1.5}\right)=\bar{q}_{l}-1.97 \frac{K_{y}}{l} \bar{h}_{o}^{1.5}
$$

where $\bar{h}_{o}=$ microscale-averaged inter-rill sheet flow depth; $\bar{q}_{l}=$ microscaleaveraged net lateral flow; $l=$ inter-rill area width; and $K_{x}^{\prime}=$ expected value of $K_{x}$ over the microscale inter-rill area width.

Equation (4) is quasi-two-dimensional. It is in one dimension, yet it contains two-dimensional properties of the inter-rill area sheet flows. In the numerical solution of this equation, one requires the average values of the model parameters over the microscale inter-rill area (Fig. 1) at each point along the $x$-direction (along the hillslope length). Such a solution is not attractive from the data collection and computational point of view. Therefore, in order to avoid such a problem and to obtain an areally-averaged conservation equation which is still local-scale but covers the length of a hillslope in the $x$-direction toward the stream, one has to average equation (4) along the hillslope length $\left(L_{x}\right)$. The general configuration that details the rill flow and inter-rill sheet flow is shown in Fig. 2. The detailed configuration of local-scale areal averaging is shown in Fig. 3. The local-scale areal averaging is performed as:

$$
\frac{1}{L_{x}} \int_{0}^{L_{x}} \frac{\partial \bar{h}_{o}}{\partial t} \mathrm{~d} x+\frac{1}{L_{x}} \int_{0}^{L_{x}} \frac{\partial}{\partial x}\left(K_{x}^{\prime} \bar{h}_{o}^{1.5}\right) \mathrm{d} x=\frac{1}{L_{x}} \int_{0}^{L_{x}} \overline{q_{l}} \mathrm{~d} x-\frac{1.97}{L_{x}} \int_{0}^{L_{x}} \frac{K_{y}}{l} \bar{h}_{0}^{1.5} \mathrm{~d} x
$$

When the integration is performed, the following equation is obtained:

$$
\frac{\partial\left\langle\bar{h}_{o}\right\rangle}{\partial t}+\frac{1}{L_{x}}\left(K_{x L_{x}}^{\prime} \bar{h}_{o L_{x}}^{1.5}\right)=\left\langle\bar{q}_{l}\right\rangle-1.97\left\langle K_{y h} \bar{h}_{o}^{1.5}\right\rangle
$$


where $\left\langle\bar{h}_{o}\right\rangle=$ local-scale areally-averaged inter-rill sheet flow depth over the length of a hillslope; $\bar{h}_{o I_{x}}=$ microscale-averaged sheet flow depth at the downstream end of the inter-rill area (hillslope bottom); $\left\langle\bar{q}_{l}\right\rangle=$ local-scale areally-averaged net lateral flow; $K_{y l}=K_{y} / l$; and $K_{x l_{y}}^{\prime}=$ is the microscale inter-rill area average of $K_{x}$ at the hillslope bottom. Note that, in the integration of the second term on the left-hand side of equation (5), the microscale-averaged sheet flow depth $\bar{h}_{0}$ at the upstream end of the local inter-rill area is assumed to be zero. The microscale-averaged inter-rill sheet flow depth profile along the hillslope length $L_{x}$ in the $x$-direction may be expressed in terms of a sine function (Govindaraju et al., 1988) as follows:

$$
\bar{h}_{o}(x, t)=h_{o L_{x}}(t) \sin \left(\frac{\pi x}{2 L_{x}}\right)
$$

When equation (7) is integrated over $L_{x}$, the following relationship is obtained between the two variables $\left\langle\bar{h}_{o}\right\rangle$ and $\bar{h}_{o L_{x}}$ :

$$
\left\langle\bar{h}_{o}\right\rangle=(2 / \pi) \bar{h}_{o l_{x}}
$$

From equations (5), (6), (7) and (8):

$$
\left\langle K_{y l} \bar{h}_{o}^{1.5}\right\rangle=\left(\frac{\pi}{2}\right)^{1.5}\left\langle\bar{h}_{o}\right\rangle^{1.5} \frac{1}{L_{x}} \int_{0}^{L_{x}} \frac{K_{y}}{l}\left[\sin \left(\frac{\pi x}{2 L_{x}}\right)\right]^{1.5} \mathrm{~d} x
$$

The integral on the right-hand side of equation (9a) is a weighted average of

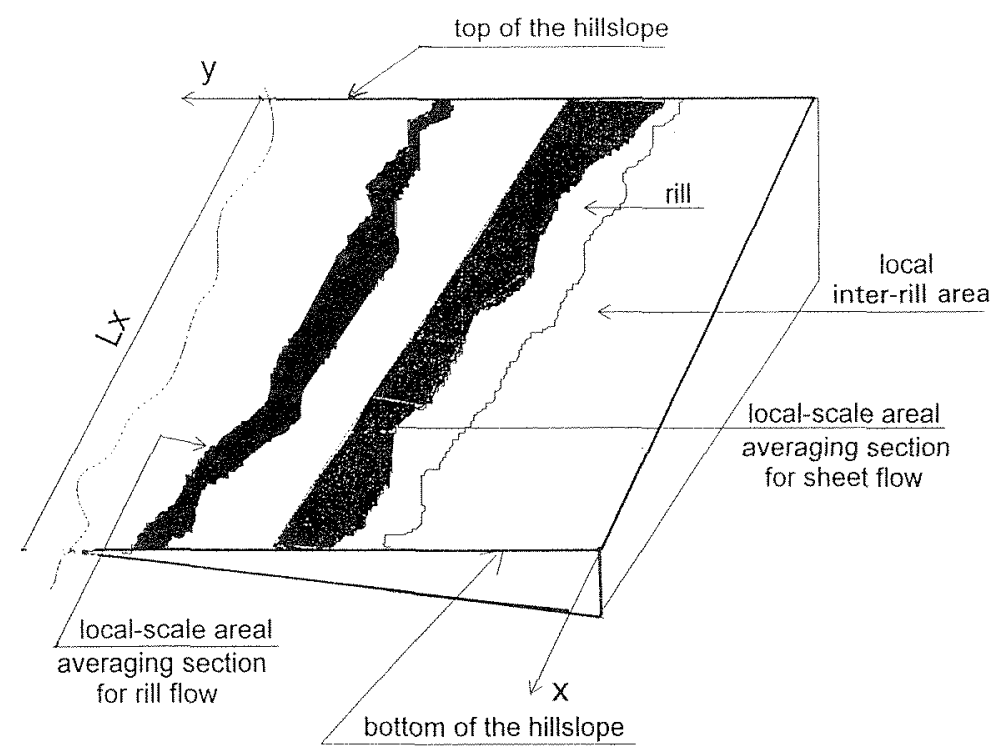

Fig. 2 Local-scale areal averaging sections for inter-rill area and rill flows. 
$K_{y}(x) / l(x)$ with a weighting factor $[\sin (\pi x / 2 l x)]^{1.5}$. Denoting this weighted average by $\left\langle K_{y l}\right\rangle$, i.e.:

$$
\left\langle K_{y \prime}\right\rangle=\frac{1}{L_{x}} \int_{0}^{L_{x}} \frac{K_{y}}{l}\left[\sin \left(\frac{\pi x}{2 L_{x}}\right)\right]^{1.5} \mathrm{~d} x
$$

and combining equations (9a) and (9b) yields:

$$
\left\langle K_{y l} \widetilde{h}_{o}^{1.5}\right\rangle=\left(\frac{\pi}{2}\right)^{1.5}\left\langle\bar{h}_{o}\right\rangle^{1.5}\left\langle K_{y l}\right\rangle
$$

For the sake of simplicity, different notation is used as follows:

$$
\begin{aligned}
& \left\langle\bar{h}_{o}\right\rangle=h_{o}^{\prime} \\
& \left\langle\bar{q}_{l}\right\rangle=q_{i}^{\prime} \\
& \left\langle K_{y l}\right\rangle=K_{y l}^{\prime}
\end{aligned}
$$

When equations (8) and (9) are substituted into equation (6), and with the new notation, the following equation is obtained as the local-scale areally-averaged interrill area sheet flow equation:

$$
\frac{\partial h_{o}^{\prime}}{\partial t}+\frac{1.97}{L_{x}}\left(K_{x L_{x}}^{\prime} h_{o}^{\prime 1.5}\right)=q_{l}^{\prime}-(1.97)^{2} K_{y l}^{\prime} h_{o}^{\prime 1.5}
$$

Equation (10), as it stands, is the local-scale areally-averaged version of the microscale-averaged inter-rill sheet flow equation (4). It conserves the mass and momentum over an individual inter-rill area located on the hillslope over the length $L_{x}$ of the hillslope. It requires only the average values of the physical model parameters (i.e. $S_{o x}, S_{o y}, C_{z}$ and $l$ ) over the whole individual inter-rill area.

\section{Local-scale areal averaging of rill flows}

The microscale-averaged (cross-sectionally averaged) rill flow equation is (Tayfur \& Kavvas, 1994):

$$
\frac{\partial h_{r}}{\partial t}+\frac{\partial}{\partial x}\left[K_{r} \frac{w_{r}^{0.5} h_{r}^{1.5}}{\left(w_{r}+2 h_{r}\right)^{0.5}}\right]=q_{l}+1.97 \bar{h}_{o}^{1.5}\left(\frac{K_{y_{1}}}{w_{r}}+\frac{K_{y_{2}}}{w_{r}}\right)
$$

where $h_{r}=$ microscale-averaged rill flow depth; $w_{r}=$ rill width; $K_{r}=C_{z r} \sqrt{S_{r x}}\left(S_{r x}\right.$ is rill bed slope and $C_{z^{\mu}}=$ Chezy roughness coefficient for rills); and $K_{y_{1}}$ and $K_{y_{2}}$ are for local inter-rill area 1 (on the right-hand side of the rill-Fig. 3) and local inter-rill area 2 (on the left-hand side of the rill-Fig. 3), respectively. The variables $K_{y_{1}}$ and $K_{y_{2}}$ are defined by equation (3). 


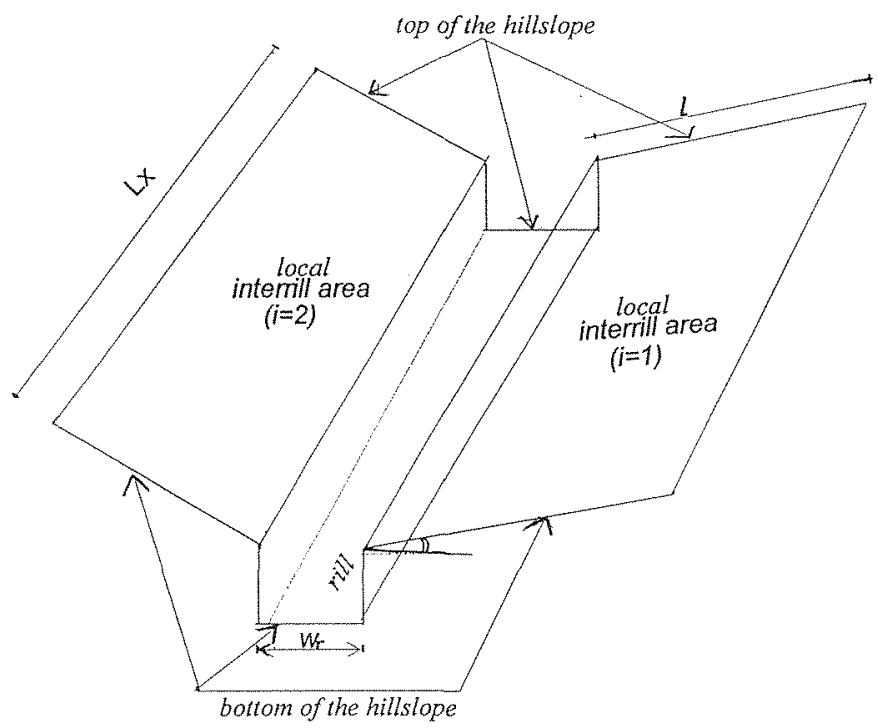

Fig. 3 Detailed representation of local-scale areal averaging sections for inter-rill area and rill flows.

Equation (11) conserves the mass and momentum at the cross-section of a rill (Fig. 1). Equation (11) assumes a rectangular cross-section for the rill (Fig. 3). The second term on the right hand side of equation (11) represents the microscale lateral fluxes coming into the rill from the adjacent inter-rill areas $(i=1,2$; two adjacent inter-rill areas (Fig. 3)). Equation (11) assumes no overflow of rills onto the inter-rill areas. It also assumes that the rill width does not change with time. The details of microscale averaging of rill flow can be obtained from Tayfur \& Kavvas (1994).

In the numerical solution of equation (11), one requires the average values of the rill cross-section parameters at each point along the $x$-direction (along the rill length down the hillslope). Such a solution is not attractive from the data collection and computational point of view. Therefore, in order to avoid such a problem and to obtain an areally-averaged conservation equation which is still local-scale but covers the length of a hillslope in the $x$-direction toward the stream, one has to average equation (11) along the hillslope length $\left(L_{x}\right)$. The general configuration that details the rill flow and inter-rill sheet flow is shown in Fig. 2. The detailed configuration of local-scale areal averaging of rill flow is shown in Fig. 3. The local-scale areal averaging of rill flow can be performed by integrating equation (11) along the length $L_{x}$ of the hillslope in the $x$-direction:

$$
\begin{aligned}
\frac{1}{L_{x}} \int_{0}^{L_{x}} \frac{\partial h_{r}}{\partial t} \mathrm{~d} x+\frac{1}{L_{x}} \int_{0}^{L_{x}} \frac{\partial}{\partial x}\left[\frac{K_{r} w_{r}^{0.5} h_{r}^{1.5}}{\left(w_{r}+2 h_{r}\right)^{0.5}}\right] \mathrm{d} x & =\frac{1}{L_{x}} \int_{0}^{L_{x}} q_{1} \mathrm{~d} x+\frac{1}{L_{x}} \int_{0}^{L_{x}} 1.97 \frac{K_{y_{1}}}{w_{r}} \bar{h}_{o}^{1.5} \mathrm{~d} x \\
& +\frac{1}{L_{x}} \int_{0}^{L_{x}} 1.97 \frac{K_{y_{2}}}{w_{r}} \bar{h}_{o}^{1.5} \mathrm{~d} x
\end{aligned}
$$

When the integration is performed, the following equation is obtained: 


$$
\frac{\partial\left\langle h_{r}\right\rangle}{\partial t}+\left[\frac{K_{R} h_{r L_{x}}^{1.5}}{\left(w_{r L_{x}}+2 h_{r L_{x}}\right)^{0.5}}\right]=\left\langle q_{1}\right\rangle+1.97\left\langle K_{Y_{1}} \bar{h}_{o}^{1.5}\right\rangle+1.97\left\langle K_{Y_{2}} \bar{h}_{o}^{1.5}\right\rangle
$$

where

$$
\begin{aligned}
& K_{R}=\left[K_{r L_{x}} w_{r L_{x}}^{0.5}\right] / L_{x} \\
& K_{y_{i}}=K_{y_{i}} / w_{r} \quad i=1,2
\end{aligned}
$$

and $\left\langle h_{r}\right\rangle=$ local-scale areally-averaged rill flow depth over the length of a hillslope; $h_{r L_{*}}=$ microscale (cross-sectionally) averaged rill flow depth at the downstream end of the rill (hillslope bottom); $K_{r L_{s}}=K_{r}$ evaluated at the bottom of the hillslope; and $w_{r L_{x}}=$ rill width at the bottom of the hillslope. Note that, in the integration of the second term on the left-hand side of equation (12), the microscale-averaged rill flow depth at the upstream end of the rill is assumed to be zero. In order to obtain a useful equation from equation (13), one needs to develop a relationship between $\left\langle h_{r}\right\rangle$ and $h_{r l_{s}}$. From the results of Govindaraju et al. (1988), such a relationship may be expressed as:

$$
h_{r}(x, t)=h_{r l_{x}}(t) \sin \left(\frac{\pi x}{2 L_{x}}\right)
$$

When equation (16) is integrated over the rill length $L_{x}$, the following relationship is obtained between the two variables $\left\langle h_{r}\right\rangle$ and $h_{r l_{x}}$ :

$$
\left\langle h_{r}\right\rangle=(2 / \pi) h_{r L_{r}}
$$

From equations (12), (13) and (7):

$$
\left\langle K_{Y_{i}} \bar{h}_{i}^{1.5}\right\rangle=\bar{h}_{v L_{x}}^{1.5}(t) \frac{1}{L_{x}} \int_{0}^{l_{x}} \frac{K_{y_{i}}}{w_{r}}\left[\sin \left(\frac{\pi x}{2 L_{x}}\right)\right]^{1.5} \mathrm{~d} x \quad i=1,2
$$

The integral on the right-hand side of equation (18a) is a weighted average of $\left[K_{y i}(x)\right] /\left[\mathcal{w}_{r}(x)\right]$ with a weighting factor $\left[\sin \left(\pi x / 2 L_{x}\right)\right]^{1.5}$. Denoting this weighted average by $\left\langle K_{Y_{i}}\right\rangle, i=1,2$, i.e.:

$$
\left\langle K_{Y_{i}}\right\rangle=\frac{1}{L_{x}} \int_{0}^{L_{x}} \frac{K_{y_{j}}}{w_{r}}\left[\sin \left(\frac{\pi x}{2 L_{x}}\right)\right]^{1.5} \mathrm{~d} x \quad i=1,2
$$

and combining equations (18a) and (18b) with equation (8) yields:

$$
\left\langle K_{Y_{i}} \bar{h}_{o}^{1.5}\right\rangle=\left(\frac{\pi}{2}\right)^{1.5}\left\langle\bar{h}_{o}\right\rangle^{1.5}\left\langle K_{Y_{i}}\right\rangle \quad i=1,2
$$


For the sake of simplicity, new notation is used as follows $(i=1,2)$ :

$$
\begin{aligned}
& \left\langle h_{r}\right\rangle=h_{r}^{\prime} \\
& \left\langle\bar{q}_{i}\right\rangle=q_{i}^{\prime} \\
& \left\langle\bar{h}_{o}\right\rangle=h_{o}^{\prime} \\
& \left\langle K_{Y_{i}}\right\rangle=K_{Y_{i}}^{\prime}
\end{aligned}
$$

When equations (17) and (18) are substituted into equation (13), and with the new notation, the following equation is obtained as the local-scale areally-averaged rill flow equation:

$$
\frac{\partial h_{r}^{\prime}}{\partial t}+\left[\frac{1.97 K_{R} h_{r}^{\prime 1.5}}{\left(w_{r t_{x}}+\pi h_{r}^{\prime}\right)^{0.5}}\right]=q_{i}^{\prime}+(1.97)^{2} h_{o}^{\prime 1.5}\left(K_{Y_{1}}^{\prime}+K_{Y_{2}}^{\prime}\right)
$$

Equation (19) is a local-scale areally-averaged version of the microscale (crosssectionally) averaged equation (11). It conserves the mass and momentum in an individual rill located along the length of a hillslope. It requires only the average values of physical model parameters of the whole rill.

\section{Hillslope-scale averaging of inter-rill area flows}

The developed local-scale areally-averaged equation (10) is for modelling inter-rill area flow over an individual inter-rill area. However, there may be many individual inter-rill areas over a whole hillslope. Therefore, it is not desirable to solve the flow at each inter-rill area. It is necessary to average the local-scale areally-averaged flow equation over the whole hillslope.

The hillslope-scale averaging is performed by the statistical averaging of equation (10) over the whole hillslope (Fig. 4):

$$
\frac{\partial\left\langle h_{o}^{\prime}\right\rangle}{\partial t}+1.97\left\langle K_{X}^{\prime} h_{o}^{\prime 1.5}\right\rangle=\left\langle q_{i}^{\prime}\right\rangle-(1.97)^{2}\left\langle K_{y i}^{\prime} h_{o}^{\prime 1.5}\right\rangle
$$

where \langle\rangle stands for the statistical average (expectation) value of a variable over the whole hillslope; $\left\langle h_{o}^{\prime}\right\rangle=$ hillslope-scale averaged inter-rill sheet flow depth; $\left\langle q_{i}^{\prime}\right\rangle=$ hillslope-scale averaged net lateral flow; and

$$
K_{X}^{\prime}=\left[K_{x L_{x}}^{\prime}\right] / L_{x}
$$

In order to obtain an explicit expression from equation (20) in terms of the statistical averages of the individual terms in equation (20), it is necessary to find the expectations of the product terms containing more than one variable in equation (20). These expectations may be found through Taylor series expansion. The Taylor series expansion 


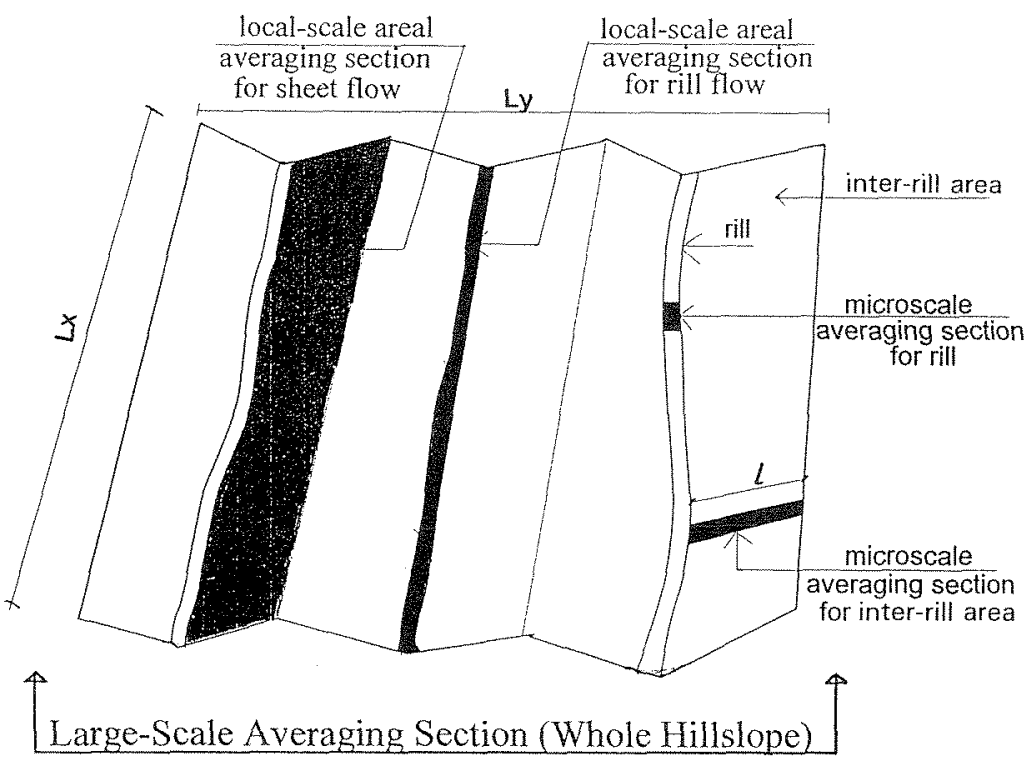

Fig. 4 Definition sketch for hillslope-scale averaging section for inter-rill area and rill flows (averaging is performed over the whole hillslope section).

for a function $\mathrm{f}(x, \bar{r})$ around $\bar{r}=\bar{r}^{\prime}$ may be expressed to second order as follows:

$$
\mathrm{f}(x, \bar{r})=\mathrm{f}\left(x, \bar{r}^{\prime}\right)+\left.\sum_{j=1}^{n}\left(r_{i}-\bar{r}_{i}^{\prime}\right) \frac{\partial \mathrm{f}(x, \bar{r})}{\partial r_{i}}\right|_{\bar{r}=\bar{r}^{\prime}}+\left.\frac{1}{2} \sum_{i=1}^{n} \sum_{j=1}^{n} \frac{\partial^{2} \mathrm{f}(x, \bar{r})}{\partial r_{i} \partial r_{j}}\right|_{\bar{r}=\bar{r}^{\prime}}\left(r_{i}-r_{i}^{\prime}\right)\left(r_{j}-r_{j}^{\prime}\right)
$$

In equation (22), $x$ represents the state variable which is, in this case, the localscale areally-averaged inter-rill sheet flow depth; $\bar{r}$ represents a set of random parameters such as slope, roughness coefficient and inter-rill area width as such, it is a random vector; and $\vec{r}^{\prime}$ is the mean value of this random vector. It is assumed that all the randomness in the state variable $x$ is due to the randomness in the parameters of the process. Such an assumption is plausible since what controls the flow dynamics are the model parameters. Therefore, any randomness that may occur in the state variable would be due to the randomness that occurs in the model parameters. Under this assumption:

$$
\langle\mathrm{f}(x, \bar{r})\rangle=\mathrm{f}\left(x, \bar{r}^{\prime}\right)+\frac{1}{2} \sum_{i=1}^{n} \sum_{j=1}^{n} \frac{\partial^{2} \mathrm{f}\left(x, \bar{r}^{\prime}\right)}{\partial r_{i} \partial r_{j}^{\prime}} \operatorname{Cov}\left(r_{i}, r_{j}\right)
$$

Applying equation (23) to equation (20):

$$
\left\langle K_{X}^{\prime} h_{o}^{1.5}\right\rangle=K_{X}^{\prime}\left(\ddot{r}^{\prime}\right) h_{o}^{\prime 1.5}\left(\bar{r}^{\prime}\right)+\frac{1}{2} \sum_{i=1}^{n} \sum_{j=1}^{n} \frac{\partial^{2}\left[K_{X}^{\prime}\left(\bar{r}^{\prime}\right) h_{o}^{\prime 1.5}\left(\bar{r}^{\prime}\right)\right]}{\partial r_{i}^{\prime} \partial r_{j}^{\prime}} \operatorname{Cov}\left(r_{i}, r_{j}\right)
$$

where the vector random variable $\bar{r}=\left(C_{z}, S_{o x}, S_{o y}, L_{x}\right)$ and $\bar{r}^{\prime}$ is its hillslope-scale mean vector.

Also in equation (20): 


$$
\left\langle K_{y /}^{\prime} h_{o}^{\prime 1.5}\right\rangle=K_{y l}^{\prime}\left(\bar{r}^{\prime}\right) h_{o}^{\prime 1.5}\left(\bar{r}^{\prime}\right)+\frac{1}{2} \sum_{i=1}^{n} \sum_{j=1}^{n} \frac{\partial^{2} K_{y l}^{\prime}\left(\bar{r}^{\prime}\right) h_{o}^{\prime 1.5}\left(\bar{r}^{\prime}\right)}{\partial r_{i}^{\prime} \partial r_{j}^{\prime}} \operatorname{Cov}\left(r_{i}, r_{j}\right)
$$

where the vector random variable $\bar{r}=\left(C_{z}, S_{o x}, S_{o y}, l\right)$ and $\bar{r}^{\prime}$ is its hillslope-scale mean vector.

When equations (24) and (25) are substituted back into equation (20) and rearranged, the following equation is obtained as the hillslope-scale averaged equation of inter-rill area sheet flows:

$$
\begin{aligned}
& \frac{\partial h_{o}^{\prime}\left(\bar{r}^{\prime}\right)}{\partial t}+0.985 \sum_{i=1}^{n} \sum_{j=1}^{n} \operatorname{Cov}\left(r_{i}, r_{j}\right)\left\{\frac{\partial^{2}\left[K_{X}^{\prime}\left(\bar{r}^{\prime}\right) h_{o}^{\prime .5}\left(\bar{r}^{\prime}\right)\right]}{\partial r_{i}^{\prime} \partial r_{j}^{\prime}}+1.97 \frac{\partial^{2}\left[K_{y l}^{\prime}\left(\bar{r}^{\prime}\right) h_{o}^{\prime 1.5}\left(\bar{r}^{\prime}\right)\right]}{\partial r_{i}^{\prime} \partial r_{j}^{\prime}}\right\} \\
& +1.97\left\{K_{X}^{\prime}\left(\bar{r}^{\prime}\right) h_{o}^{\prime 1.5}\left(\bar{r}^{\prime}\right)+1.97 K_{y^{\prime}}^{\prime}\left(\bar{r}^{\prime}\right) h_{o}^{\prime 1.5}\left(\bar{r}^{\prime}\right)\right\}=\left\langle q_{i}^{\prime}\right\rangle
\end{aligned}
$$

where $h_{o}^{\prime}\left(\bar{r}^{\prime}\right)$ is the hillslope-scale averaged inter-rill area sheet flow depth at the scale of the hillslope.

\section{Hillslope-scale averaging of rill flow}

Local-scale areally-averaged equation (19) is for modelling flow in a whole individual rill section located on a hillslope. However, the hillslope may contain a large number of rills and it is not desirable to solve the flow in each rill from computational and field work perspectives. Hence, it is necessary to average the local-scale areally-averaged rill flow equation over the whole hillslope.

The hillslope-scale averaging is performed by the statistical averaging of equation (19) over the whole hillslope (Fig. 4):

$$
\frac{\partial\left\langle h_{r}^{\prime}\right\rangle}{\partial t}+1.97\left\langle\frac{K_{R} h_{r}^{\prime 1.5}}{\left(w_{r L_{r}}+\pi h_{r}^{\prime}\right)^{0.5}}\right\rangle=\left\langle q_{l}^{\prime}\right\rangle+(1.97)^{2}\left[\left\langle K_{Y_{1}}^{\prime} h_{o}^{\prime 1.5}\right\rangle+\left\langle K_{Y_{2}}^{\prime} h_{o}^{\prime 1.5}\right\rangle\right]
$$

where $\left\langle h_{r}^{\prime}\right\rangle=$ hillslope-scale averaged rill flow depth.

Applying equation (23) to equation (27):

$$
\left\langle\frac{K_{R} h_{r}^{\prime 1.5}}{\left(w_{r_{L x}}+\pi h_{r}^{\prime}\right)^{0.5}}\right\rangle=\frac{K_{R}\left(\bar{r}^{\prime}\right) h_{r}^{\prime 1.5}\left(\bar{r}^{\prime}\right)}{\left(w_{r l_{x}}+\pi h_{r}^{\prime}\left(\bar{r}^{\prime}\right)\right)^{0.5}}+\frac{1}{2} \sum_{i=1}^{n} \sum_{j=1}^{n} \frac{\partial^{2}\left[\frac{K_{R}\left(\bar{r}^{\prime}\right) h_{r}^{\prime 1.5}\left(\bar{r}^{\prime}\right)}{\left(w_{r L_{x}}+\pi h_{r}^{\prime}\left(\bar{r}^{\prime}\right)\right)^{0.5}}\right]}{\partial r^{\prime} \partial r_{j}^{\prime}} \operatorname{Cov}\left(r_{i}, r_{j}\right)(28)
$$

where the vector random variable $\bar{r}=\left(C_{z r}, S_{r x}, w_{r}, L_{x}\right)$ and $\bar{r}^{\prime}$ is its hillslope-scale mean vector.

Also in equation (27): 


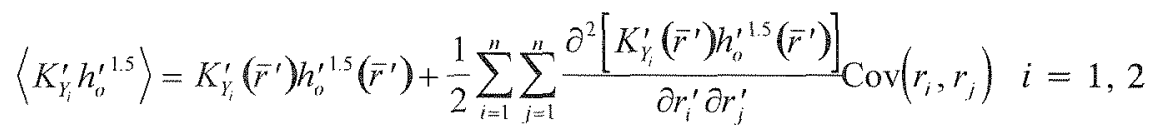

where the vector random variable $\vec{r}=\left(C_{z}, S_{o x}, S_{o y}, w_{r}\right)$ and $\vec{r}^{\prime}$ is its hillslope-scale mean vector.

When equations (28) and (29) are substituted back into equation (27) and rearranged, the following equation is obtained as the hillslope-scale averaged rill flow equation:

$$
\begin{aligned}
& \frac{\partial h_{r}^{\prime}\left(\bar{r}^{\prime}\right)}{\partial t}+0.985 \sum_{i=1}^{n} \sum_{j=1}^{n} \operatorname{Cov}\left(r_{i}, r_{j}\right)\left\{\frac{\partial^{2}\left[\frac{K_{R}\left(\bar{r}^{\prime}\right) h_{r}^{\prime 1.5}\left(\bar{r}^{\prime}\right)}{\left(w_{r L_{x}}+\pi h_{r}^{\prime}\left(\bar{r}^{\prime}\right)\right)^{0.5}}\right]}{\partial r_{i}^{\prime} \partial r_{j}^{\prime}}\right] \\
& \left.-1.97 \frac{\partial^{2}\left[K_{Y_{1}}^{\prime}\left(\bar{r}^{\prime}\right) h_{r}^{\prime 15}\left(\bar{r}^{\prime}\right)\right]}{\partial r_{i}^{\prime} \partial r_{j}^{\prime}}-1.97 \frac{\partial^{2}\left[K_{Y_{2}}^{\prime}\left(\bar{r}^{\prime}\right) h_{o}^{\prime 1.5}\left(\bar{r}^{\prime}\right)\right]}{\partial r_{i}^{\prime} \partial r_{j}^{\prime}}\right\} \\
& +1.97\left\{\frac{K_{R}\left(\bar{r}^{\prime}\right) h_{\theta}^{\prime 1.5}\left(\bar{r}^{\prime}\right)}{\left[w_{r L_{x}}+\pi h_{r}^{\prime}\left(\bar{r}^{\prime}\right)\right]^{0.5}}-1.97 h_{o}^{\prime 1.5}\left(\bar{r}^{\prime}\right)\left[K_{Y_{1}^{\prime}}^{\prime}\left(\bar{r}^{\prime}\right)+K_{Y_{2}}^{\prime}\left(\bar{r}^{\prime}\right)\right]\right\}=\left\langle q_{l}^{\prime}\right\rangle
\end{aligned}
$$

where $h_{r}^{\prime}\left(\bar{r}^{\prime}\right)$ is the hillslope-scale averaged rill flow depth at the scale of the hillslope.

To obtain the complete solution to overland flow at the scale of a hillslope, the hillslope-scale averaged inter-rill area sheet flow equation (26) and the hillslope-scale averaged rill flow equation (30) are solved simultaneously. Equation (26) is solved first in order to calculate the areal-average discharge to the stream at the hillslope bottom from the inter-rill area, and the areal-average discharge going to the rills from inter-rill areas which are located at the left-hand and right-hand sides of the rills. Then equation (30) is solved to calculate the areal-average discharge from a rill to the stream at the bottom of the hillslope. In order to find the total discharge from a hillslope to a neighbouring stream, the number of rills over a hillslope is estimated first. The probability of rill occurrence $\lambda$ is then estimated for the whole hillslope (see Govindaraju \& Kavvas, 1992; Kavvas \& Govindaraju, 1992 for details). The hillslope-scale averaged rill flow discharge to the stream is multiplied by $\lambda$, and the hillslope-scale averaged inter-rill area sheet flow discharge to the stream is multiplied by $(1-\lambda)$ in order to weigh the relative contributions of rill flows and inter-rill area sheet flows to overland flow to the neighbouring stream at the scale of a hillslope. These products are then summed to find the total discharge from a hillslope to the neighbouring stream adjacent to the particular hillslope.

The Green-Ampt infiltration model was used in the modelling of the infiltration component of the overland flow model (Rawls et al., 1983). 


\section{APPLICATION OF MODEL}

The developed model was applied in order to simulate the outflow hydrographs from two experimental hillslope plots which were constructed by researchers in the Agricultural Engineering Department of University of Kentucky to study rain-induced erosion on bare hillslopes. Each hillslope has an area of $92.4 \mathrm{~m}^{2}$ and the soil material used for these plots was silt-loam. Field facilities included a nozzle-type rainfall simulator, called Kentucky Rainfall Simulator, an electronic rill meter, a tipping bucket flow metering system, and two computer activated cameras with data packs.

The details on the construction of the plots, the Kentucky rainfall simulator, the experimental setup and procedure can be obtained from Barfield et al. (1983) and Tayfur \& Kavvas (1994). The data (provided by Barfield \& Storm, personal communication, 1989) for the experimental plots and experiments are given in Table 1.

Table 1 Results from two rainfall experiments.

\begin{tabular}{|c|c|c|c|c|c|c|}
\hline $\begin{array}{l}\text { Experimental } \\
\text { plots }\end{array}$ & \multicolumn{2}{|l|}{ Hillslope } & $\begin{array}{l}\text { Average } \\
\text { number of rills }\end{array}$ & $\begin{array}{l}\text { Rainfall } \\
\text { intensity } \\
\left(\mathrm{mm} \mathrm{h}^{-1}\right)\end{array}$ & $\begin{array}{l}\text { Rainfall } \\
\text { duration } \\
\text { (min) }\end{array}$ & $\begin{array}{l}\text { Ponding time } \\
\text { (min) }\end{array}$ \\
\hline S3R2A & 22 & 4.2 & 6 & 78 & 90 & 24 \\
\hline S2R2A & 22 & 4.2 & 6 & 97 & 90 & 20 \\
\hline
\end{tabular}

Tayfur et al. (1993) already estimated the Green-Ampt infiltration model parameters through the calibration procedure for these experimental plots as follows:

Saturated hydraulic conductivity

Available porosity

Wetting front capillary pressure head

$$
\begin{aligned}
& K=0.65 \mathrm{~cm} \mathrm{~h}^{-1} \\
& n=0.42 \\
& \Psi=18 \mathrm{~cm}
\end{aligned}
$$

These values are within the ranges suggested by Rawls et al. (1983) for silt loam soil texture. Chezy's roughness coefficient was estimated as $454 \mathrm{~mm}^{0.5} \mathrm{~s}^{-1}$ which is in agreement with the value given by Woolhiser (1975).

The estimated values of the parameters presented above were used in the numerical solution of outflow hydrographs of experimental plots, S3R2A and S2R2A. The three-dimensional pictures of these hillslopes are given elsewhere (Tayfur, 1993). From the microtopographic data for these hillslopes, the statistical averages of main ( $x$-direction in Fig. 2) and transverse (y-direction in Fig. 2) slopes were found for each hillslope. The rill distributions for these hillslopes are given elsewhere (Tayfur, 1993). From the rill distributions the statistical estimates of rill occurrence probabilities were obtained for each hillslope. The statistical averages of mean inter-rill area widths were also found for each hillslope. Since no information is available on rill width, $10 \mathrm{~cm}$ width is assumed for each rill.

The estimated statistical averages of main and transverse slopes, inter-rill area widths, and rill occurrence probabilities for each hillslope are given in Table 2. 
Table 2 Statistical information on model parameters.

\begin{tabular}{llllll}
\hline Hillslope & $\begin{array}{l}\text { Average main } \\
\text { slope }\end{array}$ & $\begin{array}{l}\text { Average } \\
\text { transverse } \\
\text { slope }\end{array}$ & $\begin{array}{l}\text { Average inter- } \\
\text { rill rill area } \\
\text { width }(\mathrm{m})\end{array}$ & $\begin{array}{l}\text { Average width } \\
(\mathrm{m})\end{array}$ & $\begin{array}{l}\text { Rill occurrence } \\
\text { probability }\end{array}$ \\
\hline S3R2A & 0.0816 & 0.0366 & 0.305 & 0.10 & 0.141 \\
S2R2A & 0.0908 & 0.0519 & 0.310 & 0.10 & 0.138 \\
\hline
\end{tabular}

Table 3 Variance and covariance values of model parameters.

\begin{tabular}{llllll}
\hline Hillslope & $\operatorname{Var}\left(S_{o x}\right)$ & $\operatorname{Var}\left(S_{o y}\right)$ & $\operatorname{Var}\left(l_{y}\right)$ & $\operatorname{Cov}\left(S_{o x} S_{o y}\right)$ & $\operatorname{Cov}\left(S_{o x} l_{y}\right)$ \\
\hline S3R2A & $1.38 \mathrm{E}-05$ & 0.00186 & 0.126 & $2.78 \mathrm{E}-04$ & $3.95 \mathrm{E}-03$ \\
S2R2A & $3.24 \mathrm{E}-04$ & 0.00112 & 0.095 & $1.02 \mathrm{E}-03$ & 0.00405 \\
\hline
\end{tabular}

Note: $S_{o x}=$ average mean slope at local scale;

$S_{o y}=$ average transverse slope at local scale; and

$l_{y}=$ average inter-rill area width at local scale.

Average rill slope was assumed to be equal to the average mean slope of inter-rill area $\left(S_{r x}=S_{a x}\right)$. The computed variance and related covariance values of model parameters are summarized in Table 3 for each hillslope. Chezy's roughness coefficient, rill width, and hillslope lengths are constant and hence, the variance and related covariance values are zero for these parameters.

Figures 5 and 6 show the simulation of outflow hydrograhs of the experimental plots S3R2A and S2R2A by the newly developed model (areally-averaged technology) presented in this study, respectively. As seen, the performance of the model is quite satisfactory in simulating both the rising and recession limbs of the observed hydrographs.

Tayfur et al. (1993) simulated the observed hydrograph of experimental plot S3R2A by the point-scale conservation equations in terms of St Venant and diffusion wave models. In the application of the point-scale technology, the detailed

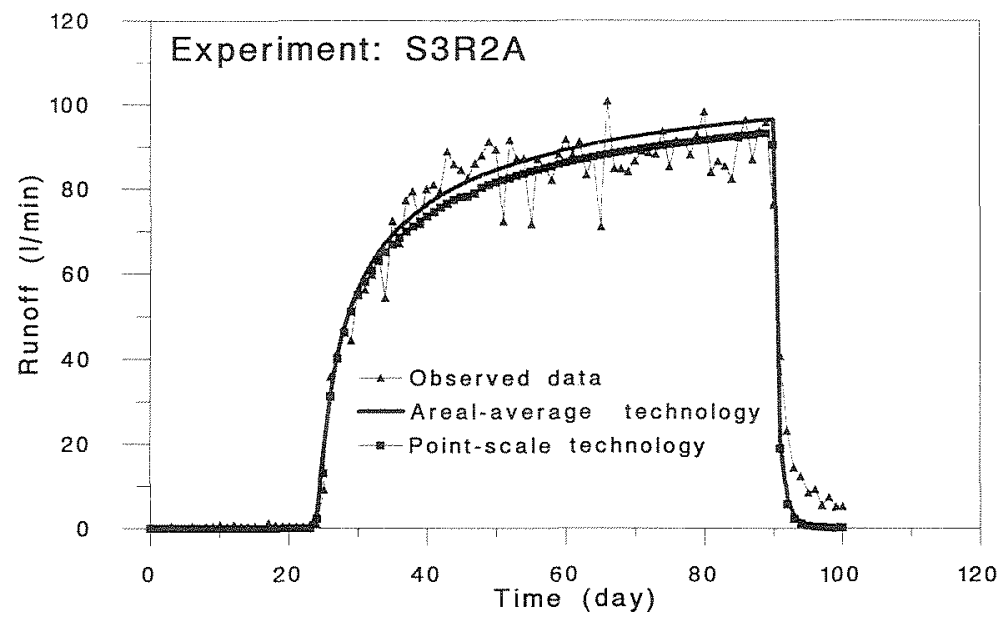

Fig. 5 Comparison of observed and simulated runoff hydrographs. 


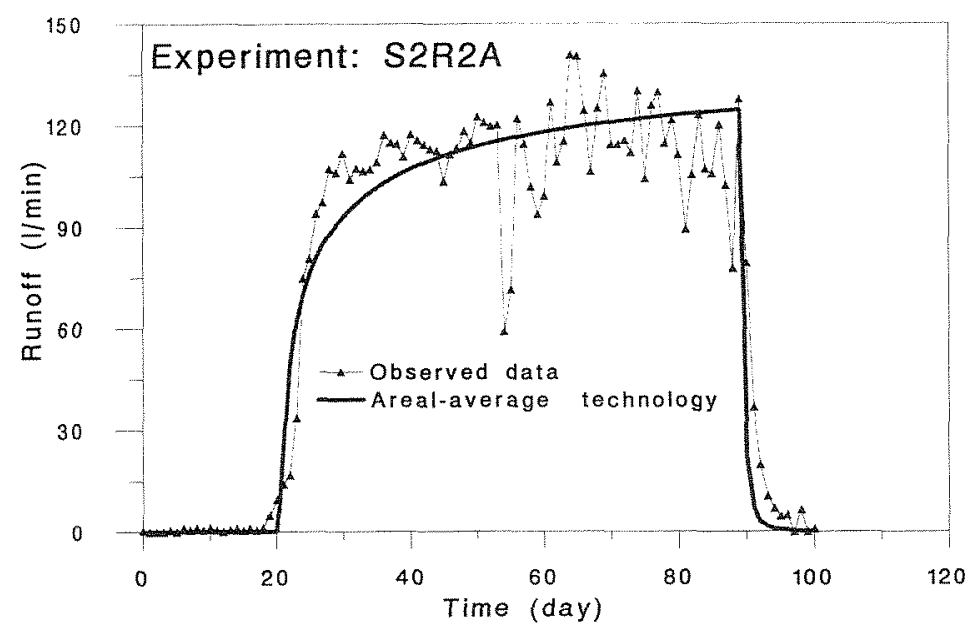

Fig. 6 Comparison of observed and simulated runoff hydrographs.

information on the microtopography of the experimental hillslope was used at a grid size of $60 \mathrm{~cm}$. Figure 5 shows the simulation of the observed hydrograph of experimental plot S3R2A by the point-scale technology (Tayfur et al., 1993) and areally-averaged technology (presented in this study). As seen in Fig. 5, the newly developed areally-averaged model performs as well as the point-scale model.

Tayfur \& Kavvas (1994) simulated the observed hydrograph of the experimental plot S2R2A by transectionally-averaged conservation equations technology. In the application of that technology only the mean slope for each hillslope transect $(4.2 \mathrm{~m}$ wide) was used. Also, Tayfur \& Kavvas (1994) employed Horton's infiltration formula for modelling the infiltration component of the overland flow model. The result of this simulation is given in Fig. 12 in Tayfur \& Kavvas (1994). When one compares Fig. 12 in that paper with Fig. 6 in the present paper, one can see that the newly developed areally-averaged equations technology performs as well as the transectionally-averaged equations technology. The comparison between Fig. 6 in the present study and Fig. 12 in Tayfur \& Kavvas (1994) is not exactly one-to-one, since different infiltration formulas were used in these models. Therefore, Fig. 12 of Tayfur \& Kavvas (1994) was not reproduced in Fig. 6 of this paper.

\section{CONCLUDING REMARKS}

In this study, a hillslope-scale areally-averaged model for quasi-two-dimensional overland flows with interacting rill flows and inter-rill area sheet flows was developed and validated by experimental data. The flow in rills is treated as onedimensional channel flow while the flow at inter-rill areas is treated as twodimensional sheet flow.

Tayfur \& Kavvas (1994) averaged two-dimensional inter-rill area sheet flow over an individual inter-rill area width in order to avoid solving the flow dynamics over 
the several nodal points at this section in two dimensions and to quantify the lateral flow going to the adjacent rill (microscale averaging). The microscale-averaged interrill area sheet flow equation and cross-sectionally averaged rill flow equation, in the present study, were then averaged along an individual inter-rill area length and individual rill length along the main flow direction ( $x$-direction in Fig. 2) down the hillslope in order to obtain local-scale areally-averaged flow equations. In this localscale areal averaging, the flow depths at the downstream ends of the individual rill and inter-rill areas were derived under the assumption that the flow profile in these sections has the profile of a sine function based upon the earlier results of Govindaraju et al. (1988). The local-scale areally-averaged equations were then averaged over a whole hillslope section to obtain hillslope-scale averaged flow equations. In the hillslope-scale averaging, it is assumed that the randomness in the state variable (flow depth) is due to the randomness in the model parameters (i.e. roughness, inter-rill area width and length, rill width and length, and $x$ - and $y$ direction slopes) which, in turn, control the state variable. Such an approach resulted in simple and easily solvable two equations with two unknowns, unlike the Tayfur \& Kavvas (1994) model with four equations and four unknowns. All the model parameters are assumed to be spatially-stationary random functions. The ensemble averages (expectations) of the terms containing more than one variable in the hillslope-scale averaged equations are obtained by the method of regular perturbation with only the first two moments being considered. The satisfactory simulation of field experimental results by the newly developed model indicates to the plausibility of the assumptions that went into the model.

The performance of the developed overland flow model for interacting rill flowsinter-rill area sheet flows at hillslope scale was tested by experimental data. The resulting simulation indicates that the developed model can simulate overland flows at hillslope scale quite well. The performance of the developed model was also compared to those of previously developed point-scale technology (Tayfur et al., 1993) and transectionally-averaged conservation equations technology (Tayfur \& Kavvas, 1994). The results of the comparisons indicate that the developed model performs as well as the others though it uses significantly less information on the land surface microtopography. For example, Tayfur et al. (1993) used transverse and main slopes at each grid nodal point when they employed the point-scale technology in terms of St Venant and diffusion wave models for modelling overland flows over the S3R2A experimental plot. They used a grid size of $60 \mathrm{~cm}$ since they had such detailed information on the microtopography of the plot. Tayfur \& Kavvas (1994), on the other hand, used average values of transverse and main slopes at each transect (which is $4.2 \mathrm{~m}$ wide) of the experimental plot S3R2A. They considered each transect thickness to be $60 \mathrm{~cm}$. Meanwhile, the newly developed model used only the average values of the transverse and main slopes for the whole hillslope section of the experimental plot.

Hillslope-scale averaging enables one to overcome the difficulties faced in estimating overland flow parameters due to heterogeneous microtopography and surface roughness conditions at the scale of a hillslope. Hillslope-scale averaged overland flow equations also circumvent the difficulties of computing overland flow at 
small grid spacing. One requires local roughness and local $x$ - and $y$-direction slope values at every nodal point of a computational network mesh over a hillslope when modelling two-dimensional overland flow by the point-scale overland flow equations. This results in a very substantial parameter estimation problem. When one models overland flow by transectionally-averaged equations (Tayfur \& Kavvas, 1994), one requires the transectionally-averaged values of one roughness coefficient, one $x$ direction slope and one $y$-direction slope over inter-rill areas, and one $x$-direction bed slope for rills at each transect of the hillslope. Though the Tayfur \& Kavvas (1994) model reduces the parameter estimation significantly, compared to the point-scale overland flow equations, it still poses a difficulty in parameter estimation due to a large number of transects on the hillslope. Meanwhile, when one models overland flows by the newly developed hillslope-scale averaged flow equations of the present study, one requires only the averaged values of one roughness coefficient, one $x$-direction slope and one $y$-direction slope over the whole inter-rill area, and one $x$-direction bed slope for all rills over the whole hillslope section. In real-world problems, one never has the detailed microtopographic information, neither at a nodal point nor at a transect. However, by means of digital elevation information (digital elevation map) with a standard resolution of about $30 \mathrm{~m}$, one can obtain estimates of hillslope-scale parameters which appear in equations (26) and (30). It is important to note that the hillslope-scale parameters in equations (26) and (30) are the averages and the covariances of the local-scale parameter values and not of the microtopographic parameter values. The parameter values which are obtained over a $30 \mathrm{~m}$ by $30 \mathrm{~m}$ grid are consistent with the scale of the local-scale parameter values. A hillslope has typical dimensions in the range of $100-500 \mathrm{~m}$ in the overland flow direction and in the range of $100-1000 \mathrm{~m}$ in the longitudinal direction (orthogonal to the overland flow direction). As such, if the hydrologist is provided with only $30 \mathrm{~m} \times 30 \mathrm{~m}$ resolution data, he/she would have in the range of 11-550 local-scale overland flow parameter sample values which could be utilized to estimate the mean $\bar{r}^{\prime}$ and the covariance $\operatorname{Cov}\left(r_{i}, r_{j}\right)$ parameters which appear in equations (26) and (30).

Acknowledgements The writers are grateful to B. J. Barfield and D. E. Storm of the Department of Agricultural Engineering, College of Agriculture, University of Kentucky, for the field experimental data (observed hydrographs) presented herein. This research was supported by US EPA (R819658) Center for Ecological Health Research at University of California, Davis. However, it does not reflect the views of the funding agency.

\section{RERERENCES}

Abrahams, A. D., Parsons, A. J. \& Luk, S.-H. (1989) Distribution of depth of overland flow on desert hillslopes and its implication for modelling soil erosion. $J$. Hydrol. 106, 177-184.

Abrahams, A. D. \& Parsons, A. J. (1990) Detemining the mean depth of overland flow in field studies of flow hydraulics. Wat, Resour. Res. 26, 501-503.

Barfield, B. I., Barnhisel, R. I., Powell, J. L., Hirschi, M. C. \& Moore, I. D. (1983) Erodibilities and eroded size distribution of Western Kentucky mine spoil and reconstructed topsoil. Institute for Mining and Minerals Research 
Final Report, Univ. of Kentucky, Lexington, Kentucky.

Enmett, W. W. (1978) Overland FLOW. In: Hillslope Hydrology (ed. by M. J. Kirkby), 145-176. John Wiley, New York.

Govindaraju, R. S., Jones, S. E., \& Kavvas, M. L. (1988) On the diffusion wave modelling for overland flow, 1. solution for steep slopes. Wat. Resour. Res. 25(5), 734-744.

Govindaraju, R. S. \& Kavvas, M. L. (1992) Characterization of the rill geometry over straight hillslopes through spatial scales. J. Hydrol. 130, 339-365.

Govindaraju, R. S., Kavvas, M. L. \& Tayfur, G. (1992) A simplified model for two-dimensional overland flows. Adv. Wat. Resour. 15, 133-141.

Kavvas, M. L. \& Govindaraju, R. S. (1992) Hydrodynamic averaging of overland flow and soil erosion over rilled hillslopes. In: Erosion, Debris Flows and Environment in Mountain Regions (Proc. Chengdu Symp., July 1992), 101-111. LAHS Publ. no. 209.

Meyer, L. D., Foster, G. R. \& Romkens, M. J. M. (1975) Source of soil eroded from upland slopes. In: Proc. 1972 Sediment Yield Workshop, US Dept. Agric. Sediment Lab. (Oxford, Mississippi), 177-189. ARS-S-40, USDA.

Moss, A. J. \& Walker, P. H. (1978) Particle transport by continental water flows in relation to erosion, deposition, soil and human activities. Sediment Geol. 20(2), 81-139.

Rawis, W. J., Brakensiek, D. L. \& Miller, N. (1983) Green-Ampt infiltration parameters from soil data. J. Hydraul. Engng ASCE 109(1), 62-70.

Tayfur, G. (1993) A hydrologic model of overland flows with interactive rill flow-sheet flow dynamics at hillslope scale. PhD Dissertation, Dept. of Civil and Environmental Engineering, Univ. of California, Davis, California.

Tayfur, G., Kavvas, M. L., Govindaraju, R. S. \& Storm, D. E. (1993) Applicability of St. Venant equations for twodimensional overland flows over rough infiltrating surfaces. $J$. Hydraul. Engng ASCE 119(1), 51-63.

Tayfur, G. \& Kavvas, M. L. (1994) Spatially averaged conservation equations for interacting rill-inter-rill area overland flows. J. Hydraul. Engng ASCE 120(12), 1426-1448.

Woolhiser, D. A. (1975). Simulation of unsteady overland flow. In: Unsteady Flow in Open Channels (ed. by K. Mahmood \& V. Yevjevich). Water Resources Publications, Fort Collins, Colorado.

Received 31 January 1997; accepted 29 August 1997 